\title{
An integrative design? How liberalised modal empiricism fails the integration challenge
}

\author{
Ylwa Sjölin Wirling ${ }^{1}$
}

Received: 1 April 2019 / Accepted: 9 October 2019 / Published online: 15 October 2019

(c) The Author(s) 2019

\begin{abstract}
The idea that justified modal belief can be accounted for in terms of empirically justified, non-modal belief is enjoying increasing popularity in the epistemology of modality. One alleged reason to prefer modal empiricism over more traditional, rationalist modal epistemologies is that empiricism avoids the problem with the integration challenge that arise for rationalism, assuming that we want to be realists about modal metaphysics. In this paper, I argue that given two very reasonable constraints on what it means to meet the integration challenge for modality, empiricism is currently at best on a par with, but potentially worse off than, rationalist alternatives, with respect to the integration challenge.
\end{abstract}

Keywords Epistemology of modality · Integration challenge · Benacerraf's problem $\cdot$ Modal empiricism $\cdot$ Modal realism

\section{Introduction}

The epistemology of modality is concerned with elucidating what is required for justified modal belief. ${ }^{1}$ Modal epistemologies of a traditional cut tend to be rationalist in nature. That is, they take the justification of modal beliefs to be had by fundamentally a priori means. Among rationalist modal epistemologies, we find Bealer's modal intuitionism (2002); the conceivability theories of Yablo (1993), Menzies (1998), and Chalmers (2002); the essence-based modal epistemologies of Lowe (2012) and Hale (2013); and the account based on grasping "principles of possibility" due to Peacocke (1999). But rationalist modal epistemologies have, perhaps always but in particular

\footnotetext{
${ }^{1}$ In what follows I will take it that not much of interest to the central issues of modal epistemology hinges on the difference between modal knowledge and justified modal belief - the relevant action is arguably with the justification-part. I will thus alternate between speaking of 'modal knowledge' and 'modal justification'.

$\bowtie \quad$ Ylwa Sjölin Wirling ylwa.wirling@gmail.com

1 Division of Philosophy, KTH Royal Institute of Technology, 10044 Stockholm, Sweden
} 
during recent years, been subject to extensive criticism. ${ }^{2}$ At the same time, the star of empiricist modal epistemologies has been steadily on the rise. According to modal empiricism, experience or experiential non-modal knowledge justifies modal beliefs. Put slightly differently, the idea is that experience is able to provide evidence of modal truth. This includes modal epistemologies according to which we can e.g. perceive a non-actual possibility directly, as Strohminger (2015) has suggested, but more common is what Fischer (2017), following McGinn (1999), calls "liberalised empiricism". 3 According to liberalised modal empiricism, modal beliefs are not directly justified via experience. Rather it is non-modal, experientially justified beliefs together with some ampliative principle of reasoning, that justifies a modal belief. The ampliative principle of reasoning in question might be e.g. inductive, abductive, analogical, or (although not strictly speaking "ampliative") deductive. In this paper, I focus on liberalised modal empiricism (and that is what I will intend with 'empiricism' in what follows). Some examples of empiricist theories in this sense are Biggs' (2011) abduction-based account, Elder's (2004, chapter 2) epistemology of essences based on the method of “flanking properties", Roca-Royes' (2017) similarity-based epistemology of de re possibilities for concrete objects, and Leon's (2017) "Moorean" approach which features a mixed bag of ordinary inference-patterns (e.g. induction, analogy) applied to uncontroversial knowledge of the actual world. ${ }^{4}$

Much (although not all) of the criticism of modal rationalism can be traced back to an alleged inability to deal with what is known as the integration challenge (Peacocke 1999) for modality. The integration challenge is the challenge to, in Peacocke's words, "reconcile a plausible account of what is involved in the truth of statements of a given kind with a credible account of how we can know those statements, when we do know them" (1999, p. 1). That is to say, from the perspective of modal epistemology, the metaphysics of modality one assumes to be correct must mesh with the epistemology of modality one is putting forward (I offer my view on what this involves in the next section). In particular, it has often been suggested that if we want to be modal realists -i.e. if we assume a metaphysics of modality that takes modal facts to be relevantly mind-independent - it is difficult to meet the integration challenge for modality as long as we are also modal rationalists. In contrast, this charge has not been directed at modal empiricism, even though its proponents tend to subscribe to modal realism. There are two possible reasons for this. Either empiricists do not need to meet the integration challenge, or modal empiricism does not present an obstacle to meeting the integration challenge, even assuming modal realism. As I will argue below, the

\footnotetext{
2 See e.g. Horvath (2014), Kung (2010), Leech (2011), Roca-Royes (2010, 2011a), Williamson (2007), and Worley (2003).

3 Not all modal epistemologies admit of being classified as "rationalist" or "empiricist". Moreover, while the use of these labels is widespread in the field, not everyone finds it very useful, see e.g. Williamson (2007) and Jenkins (2010), for instance because they think experience play an important yet non-evidential role in modal knowledge. Here however, I am concerned here with the integrative potential of accounts properly classified as empiricist, whether or not there are other ways for experience to play a role in modal epistemology.

4 Also relevant is Vetter (2016). She defends an epistemology of metaphysical modality based on gradual extrapolation from knowledge of everyday 'can'-statements (e.g. I can reach the mug; That horse can jump a $1 \mathrm{~m}$ fence). She does not give her own account of how we know 'can'-statements but points to the work of e.g. Strohminger and Roca-Royes, so presumably it is supposed to be empirically grounded.
} 
former is implausible since friends of modal empiricism extensively and repeatedly criticise rationalist modal epistemologies for not being able to meet the integration challenge, and so presumably they take the integration challenge to be important. Thus, it better be the case that modal empiricism does not face similar difficulties.

I argue in this paper that empiricists have not done enough to show that this is the case. In particular, two-by the empiricists' own lights-reasonable constraints on what it means to meet the integration challenge, gives us reason to doubt that liberalised modal empiricists are sufficiently out of the woods, as far as the integration challenge is concerned, to be in a position to criticise modal rationalists for failing to meet the very same challenge. The plan is as follows. In Sect. 2 I introduce the integration challenge as the challenge to explain why some particular method is a reliable means for getting at modal truth, given the nature of modal truth. In Sect. 3 I propose two constraints on attempts to provide such an explanation: METAPHYSICS MATTERS and NO MERE DEFERRAL. I continue in Sect. 4 by elucidating what I take to be the way in which liberalised modal empiricism is supposed to meet the integration challenge, namely by way of deferring the challenge to a domain of non-modal facts. I argue that this strategy fails to heed the NO MERE DEFERRAL constraint, because the reliability of the ampliative principle(s) remains unexplained. In Sect. 5 I argue that modal empiricists also fail to heed METAPHYSICS MATTERS. Until this is amended-and amendment requires elaboration of what the relevant version of modal realism is taken to be-modal empiricism is worse off than some of its main rationalist adversaries.

\section{The integration challenge for modality}

The integration challenge (IC) for an area-e.g. modality, mathematics, or morality-is the challenge to reconcile the epistemology and metaphysics of that area. The challenge applies to all areas where sentences are truth-apt and we want to reject scepticism. Of course, it is not equally challenging to account for integration in all areas, but modality is an area where it is often assumed to be difficult. Note though, that accounting for integration for modality does not have to be challenging. Whether it is challenging to reconcile the epistemology and metaphysics of an area depends on the theories that are taken to outline the correct nature of, and epistemic route to, modal truth. Philosophers disagree on these things, but we might say that there is an integration challenge for an area where the dominant views on the metaphysics and epistemology of that area are in tension. That said, there may be other available accounts of that area where integration is comparatively easily achieved (although these may be considered unattractive for other reasons).

Modal epistemology is concerned with the justification of modal beliefs. I assume here that whatever else is required for a method to be able to confer epistemic justification on a belief, it involves indicating the truth of that belief. From the perspective of modal epistemology then, IC is the task of explaining why - in virtue of what - the method suggested by one's theory is truth-indicative, given the modal metaphysics that is taken to underwrite these truths. It is challenging in particular when modal realism is assumed on the metaphysics-side of things. There are several different ways 
in which one can understand this explanatory challenge and what it requires. In what follows, I detail how I understand it.

First, I assume that in order for the IC for modality to be met, it is not enough that the epistemological thesis and the metaphysical thesis proposed are compatible in the weak sense of not precluding the possibility of modal knowledge/justification when both are taken to be true. Rather, the challenge is to provide some explanation, some account that elucidates how it can be that this or that method for supporting modal beliefs is somehow conducive to modal truth, given what we take modal truth to amount to. In short, we must see how the positive story is supposed to play out. ${ }^{5}$

Second, I wish to distinguish between showing that some allegedly justificatory method is truth-conducive in modal matters, and explaining why this is the case (assuming that it is). In this I am following work on the IC for mathematics, in particular due to Field (1989), which is a very common inspiration for discussion about integration in other areas. Field poses a challenge to platonists about numbers: explain the reliability of our allegedly justificatory methods in mathematics, assuming that mathematical truths are about platonic objects. ${ }^{6}$ Field suggests that this is impossible; we cannot square epistemology and metaphysics of mathematics if we insist on being platonists. Notably though, Field allows the platonist to assume the actual truth and reliability of mathematical beliefs (see also e.g. Clarke-Doane 2017, p. 21; Linnebo 2006, pp. 551-552) so the question is never whether we have reliably true mathematical beliefs, but with explaining how that can be, holding fixed some epistemology and some metaphysics of mathematics. Now, if it is possible to give an explanation of why an allegedly justificatory method is indicative of modal truth, under the assumption that it is, that can certainly be a reason (although probably not a conclusive one) to think it is a reliable guide to modal truth. But it is not the case that any reason to think that an allegedly justificatory method is reliable is also an explanation of why it is reliable.

An analogy might help to illustrate this. It is often assumed that simplicity, or parsimony, is a virtue of theories in science (and philosophy), because simple theories are more likely to be true, all else equal. Why should we accept this? There are a number of attempts to defend this assumption as far as science is concerned. One of them merely appeals to the demonstrably good track-record of simple theories over less simple theories-they deliver excellent predictive power, cool technology, and so on. This gives us reason to think that simplicity is truth-conducive. Other attempts instead aim at explaining why parsimonious theories are more likely to be true. Huemer (2009) points out:

\footnotetext{
5 This more demanding construal is in the interest of modal empiricists given that they want to criticise modal rationalists for not meeting the IC - see Sect. 3 below. For a more elaborate discussion, see my (2019a, chapter 2) and Roca-Royes (forthcoming, Sect. 5.2).

${ }^{6}$ Field, in turn, is elaborating on the problem posed by Benacerraf (1973). For similar reasoning in the case of moral realism, see Mackie (1977). Exactly what Field's challenge is supposed to be is a matter of controversy-what I offer here is my interpretation, cf. also footnote 10 below. Note however, that given my assumption in this paper that modal justification at least requires a reliable connection with modal truth, explaining modal justification involves (but need not be exhausted by) explaining the relevant method's reliability.
} 
It is worth noting, however, that the [track record argument], whether persuasive or not, makes no attempt to explain why simplicity is truth-indicative. Thus, even if it persuades sceptics of the value of simplicity, we would still need the [other] sort of explanatory theories (...) (pp. 218-219).

I take the IC to be related to the why-question, to giving an explanation, rather than to the whether-question.

Similarly, just as I take the IC to be distinct from the challenge to show that a method actually delivers true beliefs in this world, I take it to be distinct from what we may call the "modal challenge": the challenge to secure modal co-variance between beliefs and facts of an area (for authors who emphasise this latter task as the relevant one, see e.g. Baras 2017; Clarke-Doane 2017; forthcoming, chapters 4 and 5; Pust 2004). Demonstrating that some method or other is reliable with respect to modal truth does not automatically amount to meeting the IC for modality. One reason for distinguishing between meeting the IC and meeting the modal challenge is that the latter can be done without taking the nature of modal facts into account (see so-called minimalist solutions), whereas the former cannot (more on this in the next section). Relatedly — and this is also what enables minimalist solutions — when necessary truths are involved (as they clearly are here), understanding explanation of reliability in purely modal terms has odd results to say the least. ${ }^{7}$

In relation to this, it is important to address the question of why we should care about meeting the IC, since what counts as a relevant and satisfactory explanation in a given context plausibly depends partly on e.g. interest and purpose. Clarke-Doane, who emphasise the modal challenge (and the sufficiency of minimalist solutions), suggest that there is no other epistemically important sense of 'explain the reliability' besides that of securing modal co-variation. This claim must be understood against the background of his assumption that failure to explain the reliability of e.g. modal beliefs based on some method $m$, is supposed to provide us with an undercutting defeater for those beliefs. ${ }^{8}$ That is, it is important to be able to "explain the reliability" of $m$ because if we cannot, our actual, first-order beliefs based on $m$ turn out unjustified. And since meeting the modal challenge (but not the IC) suffices to deflect the threat from the undercutting defeater, that should be satisfactory (2017, p. 30; 32).

On my view, in contrast, a modal epistemology should explain the reliability of method $m$ allegedly capable of justifying modal beliefs, because doing so is an important part of supporting and elucidating that particular theory which centrally claims that $m$ is a route to justified modal belief. Assuming that true belief is the aim of modal inquiry, to put forward $m$ as able to confer justification-i.e. to give a modal epistemology - is to claim that $m$ connects modal beliefs to modal truth. Whether or not something is a modal truth depends on some fact(s). A modal metaphysics spells

\footnotetext{
7 See e.g. Baras (2017), Clarke-Doane (2015, 2017), Enoch (2010), Grundmann (2007), and Pust (2004) both for minimalist solutions and for good presentations of what happens when we understand 'explain the reliability' in modal terms when the relevant truths are necessary (which is the case even with metaphysical possibility-claims, assuming S5).

8 An undercutting defeater for the belief that $p$ is a reason to doubt that one's original evidence for $p$ is sufficiently indicative of $p$. This is different from a rebutting defeater for the belief that $p$, which is evidence for not- $p$.
} 
out the nature of those facts. So it is reasonable to expect an account of how this connection runs.

The IC is about explaining why $m$ (as specified by a modal epistemology) is reliable given some account of the truths (i.e. some modal metaphysics) it is reliable with respect to. The relevant sense of 'explain' here is to elucidate what is going on "under the hood", so to speak, of the central claim of the modal epistemology in question, i.e. that $m$ connects our modal beliefs with modal truths. It is to say in virtue of what that connection holds; to "describe the mechanism that realizes this reliability" (Grundmann 2007,p. 83); to "explain what makes it the case that the process is reliable" (Linnebo 2006, p. 563). ${ }^{9}$ If it appears impossible to meet the IC given some account(s) of modal justification and/or modality, this reflects badly on that theory. This is distinct from reflecting badly on people's actual, first-order modal beliefs (which is what e.g. Clarke-Doane takes to be the primary worry). The problem I focus on is that the theory of modal justification, on which the IC cannot be met, fails to discharge a particular explanatory burden, and this gives us a reason to reject that theory and suspect it does not give the right account of justified modal belief. ${ }^{10,11}$

\section{Two constraints}

First, in order to evaluate how well a particular modal epistemology performs with the IC, we must have some idea of what the correct modal metaphysics is taken to be. The claim that one's preferred modal epistemology can meet the IC is only meaningful in relation to some modal metaphysics or other, i.e. we must evaluate theories in pairs. A particular epistemology may go very well with one metaphysics, but not with another. Thus, there is no "metaphysics-neutral" way to meet the IC. Let's call this constraint on a solution to the IC METAPHYSICS MATTERS.

I take this constraint to be pretty natural-after all, it is hard to reconcile epistemology and metaphysics without having some particular metaphysics in mind. Moreover, as I noted above, the reason integration is challenging in an area has a lot to do with the kind of modal metaphysics one is willing to consider. In particular, the IC for modality is challenging assuming modal realism. During the last half of the 20th century, the dominating modal metaphysics took modal truths to hold in virtue of possible worlds. These were conceived of in different ways. Lewis (1986) famously takes modal truths to hold in virtue of goings-on in causally closed off, concrete worlds just like our own,

\footnotetext{
9 My emphasis in both cases.

${ }^{10}$ I said above that I take Field's challenge to be an instance of IC for mathematics. Baras, Clarke-Doane, and Pust all take Field's challenge to be the modal challenge, which I just said we should distinguish from IC. In fact, it is not at all clear from Field's original formulation (1989, pp. 25-30; 230-233) just what he thinks it takes to "explain reliability", and why it is important to do so (cf. Sjölin Wirling, 2019b). Thus, the challenge is surely open to both interpretations. For an interpretation of Field in line with mine, see David Liggins (2006, 2010, 2018).

11 Whether it also creates an undercutting defeater for modal beliefs based on the method specified by the relevant epistemology, depends on one's view on defeaters, and I do not take a stand on that here. There are some interesting parallels here to the debate about evolutionary debunking arguments in metaethics, see e.g. Clarke-Doane (2015), Vavova (2015), Tersman (2017), and Korman and Locke (forthcoming) for relevant discussion.
} 
whereas Ersatzers like Stalnaker (1976) and Plantinga (1978) take possible worlds to be abstract entities that form part of the actual world. The IC for modality seems initially difficult on all of these views, in the sense that it seems unclear how we could explain any assumed epistemological success on our part with respect to facts with such natures (concrete yet causally closed off, and abstract yet mind-independent, respectively). If we were instead attracted to e.g. Blackburn's (1993) view of modal facts as constitutively dependent on our abilities to imagine, achieving integration appears less challenging.

Given that the IC is the task to explain why a particular method is a guide to modal truth, when modal truths hold in virtue of facts with such-and-such a nature, it is presumably not enough to assume "modal realism" in general, on the metaphysics side, because not all realist modal metaphysics present the same kinds of problems (and some features may be problematic only in relations to some candidate epistemologies). In order to evaluate whether the IC can be met assuming such-and-such a modal epistemology, we must have a more specific idea of the nature of modal facts, beyond their mind-independence: are they acausal or causal; abstract or concrete; how do they relate to other facts; and so on. This does not mean that a modal epistemology cannot be "neutral" in the sense that it could potentially integrate well with several accounts of modal metaphysics that cannot simultaneously be correct. It just means that in order to evaluate whether some modal epistemology can meet the IC, we must hold fixed, for the sake of argument, some particular metaphysics of modality. ${ }^{12}$ (Of course, it takes two to tango, and so the details of the epistemology proposed also matter-but modal epistemologists hardly need to be reminded about that.) In a similar vein, Mallozzi (2018) stresses that modal metaphysics is important to modal epistemology, because our modalising must be constrained by something tracking the metaphysical grounds for modal truth in order to be reliable. Accounting for in virtue of what this tracking holds is exactly what meeting the IC amounts to, on my view, and that requires an account of what these grounds are. Mallozzi recommends modal epistemologists to proceed in a "metaphysics-first" manner, but I am here content to say that integration can only be assessed in relation to some particular modal metaphysics, and so at some point the metaphysics has to be done.

Next, the IC for modality cannot simply be deferred to another domain. Or rather, if a modal epistemology proceeds by deferring the challenge to another domain, then it must be the case that the IC for that other domain is, in turn, met. Let's call this the NO MERE DEFERRAL constraint on attempts to meet the IC. Deferral is common in modal epistemology. The basic idea is simple: construe modal knowledge as being somehow downstream from some kind of non-modal knowledge $k$. Either modal beliefs are inferred from $k$, or they essentially depend on $k$ in some other way. Deferral strategies are employed by both rationalists and empiricists. For instance, modal epistemologies that account for modal knowledge in terms of knowledge of essentialist truths use the deferral strategy, ${ }^{13}$ as do liberalised modal empiricists. They differ in what they take to be the relevant $k$. Part of the point with deferral arguably derives from concerns

\footnotetext{
12 Roca-Royes (forthcoming) also emphasises this.

13 At least insofar as the currently popular view in line with Fine (1994), according to which essence-claims are not themselves modal although they have modal implications, is assumed.
} 
with the IC: the hope is that it is easier to meet the IC for $k$ in relation to the relevant facts, than for modal beliefs in relation to modal facts. Thus, for the deferral move to be well-motivated, it is important that this is indeed the case.

Modal empiricist Roca-Royes' (2010) criticism of Peacocke's (1999) rationalist modal epistemology is instructive in seeing what NO MERE DEFERRAL dictates. She argues that although Peacocke's modal epistemology is specifically designed to meet the IC, all it manages to do is push the problem sideways. The key to Peacocke's attempt to achieve integration is something called "principles of possibility". Peacocke's preferred modal metaphysics is a linguistic ersatz-view, according to which a claim like $<\diamond$ This table breaks $>$ is true in virtue of some possible world, construed as a set of propositions, and which possible worlds there are is determined by the principles of possibility (see e.g. his 1999, Sect. 4.2). According to the modal epistemology proposed, Ethan is justified in his modal belief that it is possible that this table breaks, if he arrived at that belief through investigating a priori whether the concept 'POSSIBLE' applies to the proposition < This table breaks $>$. Thus, in order to have modal knowledge one must possess the concept 'POSSIBLE'. The principles of possibility form the possession-conditions of this concept in the sense that unless you have implicit knowledge of the principles, you do not possess the right concept 'POSSIBLE'. That is, if you possess the concept 'POSSIBLE' you have access to the set of possible worlds, because possessing the right concept involves grasping the principles of possibility, and they also determine what possible worlds there are. Now, Roca-Royes argues that possessing the right concept 'POSSIBLE' amounts to grasping certain constitutive truths, but how we might come by this understanding remains unelucidated by Peacocke. Since modal knowledge is explained in terms of grasping constitutive truths, the IC for modality has been deferred to the domain of constitutive truths. The problem is that the IC for that domain has not been met, and so there is no solution on which we might piggy-back in order to meet the IC for modality. Roca-Royes calls this the "revenge of the integration challenge" (2010, p. 340). ${ }^{14}$ More generally then, while there is nothing wrong in principle with a deferral strategy, it can only be considered successful if the IC for the deferred-to domain is indeed met.

With the notion of a deferral strategy on the table, another way in which METAPHYSICS MATTERS is important emerges. A modal epistemology that employs a deferral strategy encourages us to switch our attention from the modal beliefs themselves to some different class of, (allegedly) epistemically more basic, non-modal beliefs, and consider the method which supports them. Insofar as we care about integration, i.e. about explaining the reliability of the method in question, we also switch our attention from the modal facts to a different sort of facts, namely the facts that these non-modal beliefs are about. In order to comply with NO MERE DEFERRAL, it is important that the reliability of the non-modal method is explainable in relation to the non-modal facts, i.e. that the IC is met for the new domain. But reasonably, the IC for modality will also involve explaining why modal beliefs, based on beliefs reliable with respect to certain non-modal facts, should correspond to modal truths.

\footnotetext{
14 Roca-Royes elsewhere criticises other modal epistemologies for also (implicitly) relying on unelucidated essentialist knowledge, see (Roca-Royes 2011a, b). See also Tahko (2012) for an argument to the effect that Williamson's counterfactual-based modal epistemology does so, and Vaidya and Wallner (2018) raises a version of this problem for a number of prominent modal epistemologies.
} 
This presumably requires something of the modal facts. In particular, the move from non-modal to modal belief needs to correspond to some connection between the relevant non-modal facts and modal facts. An example will be helpful here. Lowe (2012) puts forward a modal epistemology which tries to account for our knowledge of metaphysical modality in terms of essentialist knowledge. This modal epistemology thus employs a deferral strategy. Lowe summarises his account as follows:

[I]t is part of our essence as rational, thinking beings that we can at least sometimes understand a real definition-which is just a special kind of proposition [namely those that express the essence of a thing] — and thereby grasp the essences of at least some things. Hence, we can know at least sometimes that something is metaphysically necessary or possible: we can have some knowledge of metaphysical modality (2012, p. 947).

In order for the IC to be met given this theory, what is required? Well, it must be elucidated how one can draw modal conclusions about what is possible and necessary, on the basis of essentialist knowledge. And in order to comply with NO MERE DEFERRAL it must seem plausible that the IC can be met for essentialist beliefs had by the method Lowe envisages, given the nature Lowe takes essentialist facts to have- the metaphysics of essence-facts clearly matters for that. But metaphysics also matters in another way: we need to know what essentialist facts have to do with modal facts, since this seems crucial for the idea that essentialist knowledge can justify modal beliefs. To compare, consider drawing conclusions about some unobservable entities on the basis of empirically justified beliefs about observable facts and entities - this only makes sense if we have postulated some sort of real relation between observables and unobservables. The idea here is similar.

In general, the task of connecting the relevant non-modal facts to the modal facts is a way in which METAPHYSICS MATTERS appears for deferral strategies, since elucidating this connection between two kinds of fact presumably involves some assumption about the nature of those kinds of facts. Lowe does account of the connection-his metaphysics of modality in terms of essences is a centrepiece of the view. This essentialist account of the modality certainly bears further discussion, but at least there is such an account. Similarly, on Peacocke's view outlined briefly above, the relationship between the grounds for the modal truths and the constitutive truths is quite clear.

METAPHYSICS MATTERS and NO MERE DEFERRAL are reasonable constraints on a modal epistemology that aspires to meet the IC. The former should be obvious to anyone who accepts that the IC is the challenge to reconcile epistemology with metaphysics (what else could it be?), and accepts the idea that this reconciliation involves being able to give an explanation. The latter assumption is friendly to modal empiricists, since-as will become evident in the next section-they often criticise rationalists for failing to meet the IC. If the IC were just about not precluding modal knowledge, it seems rationalists would have no particular problem. For instance, there is nothing in the conjunction of Lewisian concretism about possible worlds, and, say, some imagination-based epistemology, that preclude modal knowledge. But the problem is that things are left unexplained. Similarly, NO MERE DEFERRAL also forms the basis for some important criticism against several rationalist modal epistemologies employing deferral strategies, including Peacocke's account, as we just saw. 
In the next two sections, I will argue that current versions of liberalised modal empiricism fail to heed both constraints. I first argue that liberalised modal empiricism falls prey to a revenge of the IC, in the sense of not complying with NO MERE DEFERRAL. Then I go on to highlight how it also fails METAPHYSICS MATTERS, as it appears for deferral strategies.

\section{Integrative promise and integrative problems}

Modal empiricists do not say very much about how the IC for modality is met on their account. Yet, they often press the objection against their rationalist competitors that the latter fail to meet the IC. For instance, it is a standard critique of conceivability theory, according to which the fact that I can conceive of a world which verifies $p$ is a justifier for my belief that $p$ is possible, that it fails to answer what Vaidya (2015) calls the Connection Question: how is conceivability connected to possibility? In this vein, Kung (2010) questions the justificatory power of the imagination with respect to modal matters, on the basis of the claim that imagination has very few constraints, and the constraints that it does have seem unrelated to the utter bounds of modal truth. That is, Kung complains that we cannot see why this method would track the modal facts, i.e. imagination-based modal epistemologies have not met the IC. I already noted that Roca-Royes (2010) criticises Peacocke's modal rationalism for pushing the problem sideways rather than meeting the IC. Biggs starts off the motivation for his abduction-based modal empiricism by presenting the IC as an insurmountable task for modal rationalism (2011, pp. 287-289). Vetter (2016) writes that given modal realism, "anti-exceptionalist" modal epistemologies (to which empiricist accounts arguably belong) are much better placed than traditional, rationalist accounts, to show how modal thought manages to "hook on to reality", and see Jenkins (2008) for a very similar passage. And so on. In short, the IC is genuinely important to friends of empiricism, so it better be the case that modal empiricism can meet it.

How, then, is that supposed to happen? This is how I take it to work. Liberalised modal empiricism employs a deferral strategy. Just as some accounts defer the IC to the domain of essentialist truths, liberalised empiricists defer the IC to some (sub)domain of non-modal facts, e.g. the domain of facts about actual property instantiation. The integrative promise of empiricism, I assume, lies in the fact that this domain, to which the IC is deferred, seems relatively unproblematic. If modal justification is somehow downstream from empirically justified, non-modal beliefs, we can meet the IC for modality by meeting the IC for perceptual non-modal beliefs vis-à-vis the non-modal facts of actual property instantiation that they are about, and that we can presumably do in terms of various complex causal relations. It might thus seem as if modal empiricism has no problem heeding NO MERE DEFERRAL-rather, the deferral appears exceptionally successful, compared to deferral attempts that appeal to essentialist knowledge or knowledge of constitutive truths. ${ }^{15}$ However, modal empiricists complement empirically justified non-modal beliefs with ampliative principles, in particular inductive

\footnotetext{
15 Of course, essentialist modal epistemologists might not agree, but I will grant this much to the modal empiricists here for the sake of argument. For some recent attempts to provide an epistemology of essence, see Tahko (2018) and Mallozzi (2018).
} 
and/or abductive principles, which means that as far as integration is concerned, they cannot rest easy just yet. I will presently argue that since it is left unexplained why these principles lead us to modal truth, liberalised modal empiricism has so far failed to meet the IC.

It will be useful to have an example to work with here, and I will focus on RocaRoyes induction-based modal empiricism. ${ }^{16}$ She captures her own suggested account in slogan form like so:

We know about some entities' unrealized possibilities by extrapolation from knowledge about some other, similar entities' realized possibilities (2017, p. 233).

For instance, Darla's belief that it is possible for the (currently not-broken) glass screen of her phone to break, is justified by her experiential knowledge about other phone screens, relevantly similar to the screen of her own phone, that are actually broken. The idea, in a nutshell, is that Darla can infer this piece of modal knowledge inductively from pieces of empirically acquired non-modal knowledge that she possesses. Let $a$ be the screen of Darla's phone, and let $B<\diamond \operatorname{Cracked}(a)>$ be Darla's belief that the screen of her phone could possibly crack. According to the slogan then, Darla is justified in holding $B<\diamond \operatorname{Cracked}(a)>$ on the basis of justified non-modal belief about actuality. First, she believes that $a$ is a glass phone screen, i.e. she holds $B<\operatorname{GPS}(a)>$. She believes this on the basis of empirical evidence, e.g. she can see it, feel it, hear it if she taps it with her nail, and she has read the product specifications on the back of the box the phone came in. Second, she holds beliefs $B<\operatorname{GPS}(b)>$ and $B<\operatorname{GPS}(c)>$, where $b$ is the screen of her previous phone, and $c$ is the screen of her brother's phone, for similar reasons. Third, she beliefs that both $b$ and $c$ actually instantiate the property of being cracked, i.e. she holds $B<\operatorname{Cracked}(b)>$ because she saw it crack, and $B<\operatorname{Cracked}(c)$ because her brother, who dropped it, told her. Let's grant that these are all perfectly fine, empirically justified beliefs, supported by methods for which the IC can be met.

In order to get from these beliefs about actual property instantiation to the modal belief $B<\diamond \operatorname{Cracked}(a)>$, Darla relies on induction. On the basis of her beliefs about $b$ and $c$ (and perhaps other similar entities too), she holds a (perhaps tacit) belief in a principle along the lines of $\forall x(\operatorname{GPS}(x) \rightarrow \diamond \operatorname{Cracked}(x))$. This is what Roca-Royes calls "nomic-like knowledge" (2017, pp. 229-230). Together with the belief that $<\operatorname{GPS}(a)\rangle$ is true, it clearly follows from this principle that it is possible that $a$ cracks (since $a$ is a phone screen and if something is a phone screen it can possibly crack, according to the principle). The crucial work for induction is to support the relevant nomic belief (which is clearly a modal belief). But in order to get the right principle from these empirically justified beliefs, using induction, we also need to add the belief that actuality implies possibility, in this case that $<\operatorname{Cracked}(b) \rightarrow \diamond \operatorname{Cracked}(b)>$ (which Roca-Royes takes to be a conceptual truth, grasped in whatever way we grasp such truths).

Has the IC been met for this account, assuming modal realism? We have granted that the IC is met for perceptually justified beliefs about actual property instantiation.

\footnotetext{
16 Her account is arguably the most detailed liberalised empiricist candidate to date. See also Elder (2004) and Leon (2017) for other empiricist examples that partly appeal to induction, and see Biggs (2011) for an empiricist account which appeals to abduction.
} 
Let's also grant, for the sake of argument, that there is no issue with integration for the principle that actuality implies possibility. ${ }^{17}$ But what about the inductive reasoning doing all the heavy lifting here, has its reliability been explained $?^{18}$ Differently put, has the IC for induction been met?

To the extent that the matter is discussed by Roca-Royes, she notes that while there is certainly an interesting and difficult question concerning what she calls the "epistemic adequacy"19 of ampliative methods like induction more generally, there is no special problem for an epistemology of modality that also uses induction (2017, pp. 230-232). What does this mean? Well, either we do have enough of an explanation of the reliability of induction, or we do not. It is certainly an open question. RocaRoyes notes that in principle we can test whether induction delivers the right results in the case of de re possibility beliefs (2017, p. 232). In the example of Darla's belief, we can attempt to break the phone screen after she has formed the belief that it can possibly break, using the method outlined above. We could do this over and over with different phone screens, and with different entities that are similar in other respects. Given enough data, if the success rate-the ratio of true modal beliefs arrived at through the given method-is high enough, we could say that it is a reliable method for forming that kind of modal beliefs. This might be terribly cumbersome an experiment in practice, but as a test of in-fact reliability, it is perfectly straight-forward. Moreover, isn't it natural and highly intuitive to think, after observing instances of similar entities actually instantiating some property, that this entity here could also possibly instantiate that property? We take induction as justification-conferring in many contexts, so why shouldn't it be here too?

I have no quarrel with either testability or intuitiveness here. But neither point speaks to the issue of integration. Again, the IC is not primarily about giving reasons to think that a particular method is a reliable guide to modal truth, but with elucidating why it is supposedly reliable (although, again, if the IC can be met that might itself be a reason to think that the method in question is indeed reliable). Recall the analogous case of simplicity as a theoretical virtue: empirical evidence that simple theories are often true is not an explanation of simplicity's truth-conduciveness. So none of this does anything to indicate what explains the reliability of induction. It should be clear that the situation is similar for liberalised modal empiricists that rely on another ampliative principle, like abduction, such as Biggs (2011). It far from evident that we have enough of an explanation of why abduction is reliable-we have less of it than in the case of induction, I suspect. ${ }^{20}$

\footnotetext{
17 One could raise the question of whether the reliability of our method for coming to know conceptual truths really do meet the IC, and insist that the modal empiricist say something about this as well. I won't pursue that here.

18 Note though, that the explanatory task here is not the same as the task to independently justify e.g. induction or abduction - that would be a tall order indeed-since one is allowed to assume the reliability of the method in explaining it.

19 This way of phrasing it is unfortunately a bit vague, but I will consider this as pertaining to the IC.

20 Abduction, when conceived of as a form of inference to the best explanation (in line with Biggs' paper) involves assessing which out of several candidates perform best in relation to a number of abductive principles like simplicity, parsimony, comprehensiveness, etc. Meeting the IC given abductive modal empiricism thus involves addressing why a combination of these principles reliably indicates modal truth. (For a fuller discussion of Biggs' abductive modal epistemology, see my 2019a, Sect. 3.2.2.).
} 
And if we do not have an explanation of induction (or abduction) more generally, it is not clear how this fact could be of any consolation to the modal empiricist, since the result is still that the IC has not been met:

P1. In order to meet the IC for modality, NO MERE DEFERRAL and METAPHYSICS MATTERS must be respected.

P2. Liberalised modal empiricism fails to respect NO MERE DEFERRAL (from P2a, $\mathrm{P} 2 \mathrm{~b})$.

P2a. Liberalised modal empiricism defers to perceptual knowledge and to induction/abduction.

P2b. It is not clear how the reliability of induction/abduction can be explained.

C1. Liberalised modal empiricism fails to meet the IC for modality.

Modal empiricists criticize modal rationalists for not meeting the IC for modality. But if the IC as it applies to induction/abduction has not been met either, that puts empiricists in a poor place to criticise rationalists for failing in this particular regard.

There might be an additional problem, even assuming for the sake of argument that there is enough of a (although perhaps partial or sketch-like) explanation of the ampliative principle's reliability. The hope is, I take it, for liberalised modal empiricism to free-ride on whatever that explanation turns out to be. But there is a general obstacle for such free-riding attempts. Again, we may consider the analogy with simplicity. It is sometimes said that since simplicity is demonstrably truth-indicative in the context of science, we may assume that it is truth-indicative in the context of philosophy too. But as Huemer points out:

Presumably there is some reason why simplicity is truth-indicative (...). In the absence of (...) identification [of this reason], the assumption that this reason applies equally well to philosophy as science is something of a leap of faith (2009, p. 229).

Analogously, presumably there is some explanation of why e.g. induction or abduction leads us to mainly true beliefs in certain contexts. But unless we see that explanation, it is hard to say whether it will also apply in the context of the relevant modal beliefs. This is easiest to see with abduction, I think. Say that there is a reason why applying a combination of theoretical virtues reliably indicates truth in non-modal contexts, and so this practice justifies non-modal belief. The point of IC is that a story of justification must make sense in light of the story of the facts. But remember that a prominent reason for considering the IC to be especially difficult for a domain like modality has to do with the nature modal facts are taken to have, and many have clearly thought that modal facts are not like non-modal facts in various epistemically relevant aspects. So whether the explanation will carry over to the modal context depends both on the explanation, and on the nature of the modal facts. Hence to assess the success of a particular free-riding attempt, we will need to hear more about the modal metaphysics. This leads on to the problem with liberalised modal empiricism to be addressed in the next section, which is simply that they say too little about that. 
In sum, a deferral strategy is a way to meet the IC for modality only if the corresponding challenge is met for the domain to which it is deferred. Liberalised empiricist epistemologies defer the challenge to both perception of actual property instantiation, and ampliative principles like induction and abduction. While the IC can presumably be met for perception of actual properties of ordinary objects, it is not clear that the IC can be met for these ampliative modes of reasoning. Hence, liberalised modal empiricism fails NO MERE DEFERRAL. Until further work has been done, empiricists will be no better off than the rationalists who, according to empiricist criticism, fall prey to a revenge of the IC-often as result of their deferral strategy (e.g. reliance on unelucidated knowledge of essence, for which the IC has not been met).

\section{Making modal metaphysics matter}

I suggest that there is also the following gap in the empiricists' integrative story: they have neglected to hook the modal facts up to the picture they are painting, and so fails to heed METAPHYSICS MATTERS as it appears for deferral strategies. I said in Sect. 3 that modal metaphysics still matters for the integration of deferral modal epistemologies in the sense that the relevant non-modal facts must presumably have something to do with the modal facts, if we are to explain how one can draw justified modal conclusions on the basis of knowing about some non-modal facts. No one would, I assume, suggest that Lowe wouldn't need to spell out the relation he envisions between modal facts and essentialist facts as part of his epistemology of modality. This does not mean that it is mandatory for an essence-based modal epistemology to endorse that essentialist facts are metaphysically prior to modal facts (although this is how Lowe chooses to cash the relationship out). But the proponent of such a modal epistemology owes us some account of the relation between modal and essentialist truth. It is the relevant metaphysics of modality which props up the claim that we can reason from essentialist knowledge to modal knowledge-if essentialist truths had nothing to do with modal truths, that suggestion would appear unsupported.

The reminder appears unnecessary in the case of essentialist knowledge-perhaps because it strikes us as suspect in a way which empirical knowledge does not, so the demand for an elucidation comes naturally to us there. But it is important to note that if we hold modal epistemologies to this standard, it also applies to liberalised modal empiricism. Just as we want to know in virtue of what essentialist knowledge can epistemically support modal beliefs, we should ask in virtue of what non-modal knowledge of actual property instantiation can epistemically support modal beliefs. To just say that induction can take us from one to the other is as unsatisfying as saying that we can reason from one to the other in the case of essentialist knowledge and modal knowledge, unless we are informed about some underlying relation between the two kinds of facts. We might intuitively feel as if we know what is going on, as soon as the context is inference from ordinary, hum-drum non-modal beliefs, and perhaps we are epistemically blameless in making these inferences, but the IC is not about that, just as it is not about demonstrating reliability. It is about being able to explain the promise of epistemic success that the modal epistemologist claims for her preferred method. 
But liberalised modal empiricists are typically silent on what they take to be the nature of modal facts. Either they say nothing about modal metaphysics at all (e.g. Leon 2017; Roca-Royes 2017), or they make an unspecific commitment to modal fact as mind-independent and "unobservable", but nothing more (e.g. Biggs 2011). In particular, nothing is said about how modal facts relate to the non-modal facts that allegedly provide us with modal knowledge. Until they do say something about this, it is very difficult to evaluate whether the IC, assuming modal realism, can be met by liberalised modal empiricism.

I am not suggesting that empiricists could not amend this by elaborating on the underlying metaphysical story, or that empiricists would need to appeal to some particularly implausible or problematic kind of modal metaphysics. ${ }^{21}$ And as it turns out, elaboration on the relevant metaphysics will also be involved in meeting NO MERE DEFERRAL: whatever the explanation of the truth-conduciveness of induction/abduction is, we will need to have an idea of the metaphysics of modality in order to deflect the worry about the free-riding strategy, as noted above. Hence, the empiricist could potentially kill two birds with one stone here-providing the modal metaphysics is key to meeting both constraints. But the point is that until we have the story, it cannot be properly evaluated, and until then we cannot say that modal empiricism is in a better position with respect to integration than deferralist competitors that base modal knowledge on rationalist knowledge of some kind or other-especially insofar as the connection between modal facts and facts in the deferred-to domain arguably has been elucidated on rationalist accounts like Peacocke's and Lowe's. Building on the argument stated in the previous section, we can summarise the situation as follows ${ }^{22}$ :

P1. In order to meet the IC for modality, NO MERE DEFERRAL and METAPHYSICS MATTERS must be respected.

P2. Liberalised modal empiricism fails NO MERE DEFERRAL (from P2a, P2b).

P2a. Liberalised modal empiricism defers to perceptual knowledge and to induction/abduction.

P2b. It is not clear how the IC for induction/abduction can be met.

P3. Liberalised modal empiricism fails to respect METAPHYSICS MATTERS (from P3a).

P3a. The connection between modal and non-modal facts has not been elucidated.

C1. Liberalised modal empiricism fails to meet the IC for modality.

P4. Rationalist modal epistemologies (e.g. Lowe's essence-based and Peacocke's principles of possibility) fail to respect NO MERE DEFERRAL (from P4a).

P4a. Rationalist modal epistemologies rely on or defer to methods for which it is not clear how the IC can be met.

\footnotetext{
${ }^{21}$ It is beyond the scope of this paper to explore what modal metaphysics would be suitable. One interesting possibility might be to investigate how Vetter's (2015) account of modal truth as grounded in dispositions of individual objects fares in combination with some form of liberalised modal empiricism, as an anonymous reviewer pointed out to me.

22 Of course, I have not done anything to defend P4a in this paper, and as previously noted friends of essence-based accounts may well disagree. I am granting this point to empiricists for the sake of argument.
} 
P5. Rationalist modal epistemologies do respect METAPHYSICS MATTERS (from P5a).

P5a. The connection between essentialist/constitutive facts and modal facts is clear.

C2. Rationalist modal epistemologies fail to meet the IC for modality.

The master conclusion of this argument, with $\mathrm{C} 1$ and $\mathrm{C} 2$ taken together, is that both kinds of theory fail to meet the IC. Thus, at best, these rationalists and liberalised empiricists are equally bad off. Notably however, liberalised empiricism seems potentially worse off than prominent rationalist alternatives, in the sense that it respects neither constraint, whereas these rationalists arguably respect METAPHYSICS MATTERS.

\section{Conclusions}

I have argued that liberalised modal empiricism is not, contrary to what is often assumed, obviously better off with respect to the IC for modality than certain traditional, rationalist modal epistemologies. In fact, it may be worse off, even granting empiricists their standard integration critique against rationalist modal epistemology. I argued that NO MERE DEFERRAL and METAPHYSICS MATTERS are both reasonable constraints on any attempt to meet the IC, by the empiricists' own lights. Liberalised modal empiricism fails to respect NO MERE DEFERRAL because it is not clear how the truth-conduciveness of the ampliative principles doing all the work is to be explained. Hence, there is a potential "revenge" of the IC, akin to that which faces (some prominent versions of) modal rationalism, according to empiricist critics. Liberalised modal empiricism also fails to respect METAPHYSICS MATTERS as it appears for deferral strategies, because too little has been said about the relevant form of modal realism that is assumed on the metaphysics-side of things, and in particular about how modal facts relate to the non-modal facts that supposedly inform us about modal matters (with the help of ampliative principles). Prominent rationalist alternatives, on the other hand, appear to respect METAPHYSICS MATTERS. Until more work has been done by the empiricist in response to these two issues, it cannot reasonably be assumed that empiricism is more promising with respect to the IC.

Of course, the empiricist could instead reject the requirement that a modal epistemology should be able to meet the IC. But then she cannot heap integration-related criticism on her rationalist rivals, and since the IC is lurking behind much traditional critique of rationalist modal epistemology, this may have unpalatable dialectical consequences. Rejecting the explanatory IC in favour of weak compatibility also undermines the critique against rationalists, and so is not in the empiricists' interest. The best option for modal empiricists seems to be to take the IC for modality seriously, and get cracking on the positive story available given her own view, assuming some more particular form of modal realism. ${ }^{23}$

23 Given that I have argued that empiricists have not yet met the IC, might it not be suspected that the challenge is so demanding that no modal epistemology can meet it? First of all, it is not part of my argument that empiricists cannot flesh out their accounts in order to meet the IC. For all I have said, it may well be 
Finally, as I noted early on, the IC is not unique to modality but arises for most areas of philosophical interest, although it is not always equally challenging to achieve integration. Whether it is hard or easy, again, depends on what kind of metaphysics and what kind of epistemology are taken to be in the right ballpark for that area. Can we learn anything about the IC for other areas, from what I have argued here? Yes, certainly: METAPHYSICS MATTERS and NO MERE DEFERRAL applies for the IC in all areas, and so they can be used to assess the integrative success of accounts-empiricist and otherwise - in areas outside of modality. However, one aspect of the point I am making here is that how the IC is to be met for a given area, and whether empiricist epistemologies are promising alternatives for that area when it comes to integration, depends very much on what the correct metaphysics of that domain is taken to be. ${ }^{24}$ In other words, while we can certainly look for inspiration in other seemingly similar domains when we consider possible ways to explain reliability in the sense relevant here, meeting the IC in a domain always involves carefully considering the particular candidate metaphysics and epistemologies available for that particular domain.

Acknowledgements Open access funding provided by Royal Institute of Technology. I wish to thank AnnaSofia Maurin, Sónia Roca-Royes, Sören Häggqvist, and Tuomas Tahko for very useful discussion of the ideas in this text. I am also grateful to several anonymous reviewers of this journal for their careful readings and helpful comments, which served to greatly improve this paper.

Open Access This article is distributed under the terms of the Creative Commons Attribution 4.0 International License (http://creativecommons.org/licenses/by/4.0/), which permits unrestricted use, distribution, and reproduction in any medium, provided you give appropriate credit to the original author(s) and the source, provide a link to the Creative Commons license, and indicate if changes were made.

\section{References}

Baras, D. (2017). Our reliability is in principle explainable. Episteme, 14(2), 197-211.

Bealer, G. (2002). Modal epistemology and the rationalist renaissance. In T. S. Gendler \& J. Hawthorne (Eds.), Conceivability and possibility (pp. 71-125). Oxford: Oxford University Press.

Benacerraf, P. (1973). Mathematical truth. Journal of Philosophy, 70(19), 661-679.

Biggs, S. (2011). Abduction and modality. Philosophy and Phenomenological Research, 83(2), $283-326$.

Blackburn, S. (1993). Morals and Modals. In S. Blackburn (Ed.), Essays in quasi-realism. Oxford: Oxford University Press.

Chalmers, D. (2002). Does conceivability entail possibility? In T. S. Gendler \& J. Hawthorne (Eds.), Conceivability and possibility (pp. 145-200). Oxford: Clarendon Press.

Clarke-Doane, J. (2015). Justification and explanation in mathematics and morality. In R. Shafer-Landau (Ed.), Oxford studies in metaethics (pp. 80-103). Oxford: Oxford University Press.

Clarke-Doane, J. (2017). What is the Benacerraf problem? In F. Pataut (Ed.), New perspectives on the philosophy of paul Benacerraf: truth, objects, infinity (pp. 17-43). Switzerland: Springer.

Footnote 23 continued

done. Second, I have not discussed the prospects of rationalist theories in any detail here but just granted empiricists that, as traditionally assumed, rationalism has problem with integration. Rationalists, of course, might not agree and are free to formulate explanations in response to the IC. Third, that the IC cannot be met at all seems plausible only as long as we are assuming modal realism, so one thing that might imply is that we need to give up modal realism, not that there is anything wrong with the challenge. But of course, we could conclude that the IC is not a reasonable demand to place on modal epistemologies. Again, as noted above, this may greatly impact the traditional dialectics in the field and call for revision of many oft-repeated arguments. Thanks to an anonymous reviewer for prompting me to say something about this.

24 See Liggins (2018) for a similar point in relation to Field's challenge as it appears for mathematical platonism. 
Clarke-Doane, J. (forthcoming). Morality and mathematics. Oxford: Oxford University Press.

Elder, C. L. (2004). Real natures and familiar objects (Vol. 2). Cambridge, MA: MIT Press.

Enoch, D. (2010). The epistemological challenge to metanormative realism: How best to understand it, and how to cope with it. Philosophical Studies, 148(3), 413-438.

Field, H. (1989). Realism, mathematics \& modality. Oxford: Basil Blackwell.

Fine, K. (1994). Essence and modality. Philosophical Perspectives, 8, 1-16.

Fischer, B. (2017). Modal empiricism: Objection, reply, proposal. In B. Fischer \& F. Leon (Eds.), Modal epistemology after rationalism (pp. 263-279). Dordrecht: Springer.

Grundmann, T. (2007). The nature of rational intuitions and a fresh look at the explanationist objection. Grazer Philosophische Studien, 74(1), 69-87.

Hale, B. (2013). Necessary beings. Oxford: Oxford University Press.

Horvath, J. (2014). Lowe on modal knowledge. Thought A: Journal of Philosophy, 3(3), 208-217.

Huemer, M. (2009). When is parsimony a virtue? Philosophical Quarterly, 59(235), 216-236.

Jenkins, C. S. (2008). Grounding concepts: An empirical basis for arithmetical knowledge. Oxford: Oxford University Press.

Jenkins, C. S. (2010). Concepts, experience and modal knowledge. Philosophical Perspectives, 24(1), 255-279.

Korman, D. Z., \& Locke, D. (forthcoming). Against minimalist responses to moral debunking arguments. Oxford Studies in Metaethics.

Kung, P. (2010). Imagining as a guide to possibility. Philosophy and Phenomenological Research, 81(3), $620-663$.

Leech, J. (2011). Modal rationalism. Dialectica, 65(1), 103-115.

Leon, F. (2017). From modal skepticism to modal empiricism. In B. Fischer \& F. Leon (Eds.), Modal epistemology after rationalism (pp. 247-261). Dordrecht: Springer.

Lewis, D. (1986). On the plurality of worlds. Oxford: Blackwell.

Liggins, D. (2006). Is there a good epistemological argument against platonism? Analysis, 66(290), 135-141.

Liggins, D. (2010). Epistemological objections to platonism. Philosophy Compass, 5(1), 67-77.

Liggins, D. (2018). The reality of field's epistemological challenge to platonism. Erkenntnis, 83(5), $1027-1031$

Linnebo, Ø. (2006). Epistemological challenges to mathematical platonism. Philosophical Studies, 129(3), $545-574$.

Lowe, E. J. (2012). What is the source of our knowledge of modal truths? Mind: A Quarterly Review of Philosophy, 121(484), 919-950.

Mackie, J. L. (1977). Ethics: Inventing right and wrong. Harmondsworth: Penguin.

Mallozzi, A. (2018). Putting modal metaphysics first. Synthese. https://doi.org/10.1007/s11229-018-18282.

McGinn, C. (1999). Knowledge and reality: selected essays. New York: Oxford University Press.

Menzies, P. (1998). Possibility and conceivability: A response-dependent account of their connections. In R. Casati (Ed.), European review of philosophy, volume 3: Response-dependence (pp. 255-277). Stanford: CSLI Publications.

Peacocke, C. (1999). Being known. Oxford: Clarendon Press.

Plantinga, A. (1978). The nature of necessity. Oxford: Clarendon Press.

Pust, J. (2004). On explaining knowledge of necessity. Dialectica, 58(1), 71-87.

Roca-Royes, S. (2010). Modal epistemology, modal concepts and the integration challenge. Dialectica, 64(3), 335-361.

Roca-Royes, S. (2011a). Conceivability and de re modal knowledge. Nô̂s, 45(1), 22-49.

Roca-Royes, S. (2011b). Modal knowledge and counterfactual knowledge. Logique et Analyse, 54(216), $537-552$.

Roca-Royes, S. (2017). Similarity and possibility: An epistemology of de re possibility for concrete entities. In B. Fischer \& F. Leon (Eds.), Modal epistemology after rationalism (pp. 221-245). Dordrecht: Springer.

Roca-Royes, S. (forthcoming). The integration challenge. In O. Bueno, \& S. A. Shalkowski (Eds.), The Routledge handbook of modality.

Sjölin Wirling, Y. (2019a). Modal empiricism made difficult: An essay in the meta-epistemology of modality. Doctoral dissertation, University of Gothenburg. 
Sjölin Wirling, Y. (2019b). What is field's epistemological objection to platonism? In R. Stenwall, \& T. Hansson-Wahlberg (Eds.), Maurinian truths (pp. 123-133). Lund. Available at: http://lup.lub.lu.se/ record/35448559-6bf9-4974-8663-ee04ff83a679

Stalnaker, R. C. (1976). Possible worlds. Nô̂s, 10(1), 65-75.

Strohminger, M. (2015). Perceptual knowledge of nonactual possibilities. Philosophical Perspectives, 29(1), $363-375$.

Tahko, T. E. (2012). Counterfactuals and modal epistemology. Grazer Philosophische Studien, 86(1), 93-115.

Tahko, T. E. (2018). The epistemology of essence. In A. Carruth, S. C. Gibb, \& J. Heil (Eds.), Ontology, modality, mind: Themes from the metaphysics of E. J. Lowe (pp. 93-110). Oxford: Oxford University Press.

Tersman, F. (2017). Debunking and disagreement. Noûs, 51(4), 754-774.

Vaidya, A. J. (2015). The epistemology of modality. In E. N. Zalta (Ed.), The Stanford encyclopedia of philosophy (Summer 2015 ed.).

Vaidya, A. J., \& Wallner, M. (2018). The epistemology of modality and the problem of modal epistemic friction. Synthese. https://doi.org/10.1007/s11229-018-1860-2.

Vavova, K. (2015). Evolutionary debunking of moral realism. Philosophy Compass, 10(2), 104-116.

Vetter, B. (2015). Potentiality: From dispositions to modality. Oxford: Oxford University Press.

Vetter, B. (2016). Williamsonian modal epistemology, possibility-based. Canadian Journal of Philosophy, 46(4-5), 766-795.

Williamson, T. (2007). The philosophy of philosophy. Malden: Blackwell Publishing.

Worley, S. (2003). Conceivability, possibility and physicalism. Analysis, 63(1), 15-23.

Yablo, S. (1993). Is conceivability a guide to possibility? Philosophy and Phenomenological Research, $53(1), 1-42$.

Publisher's Note Springer Nature remains neutral with regard to jurisdictional claims in published maps and institutional affiliations. 